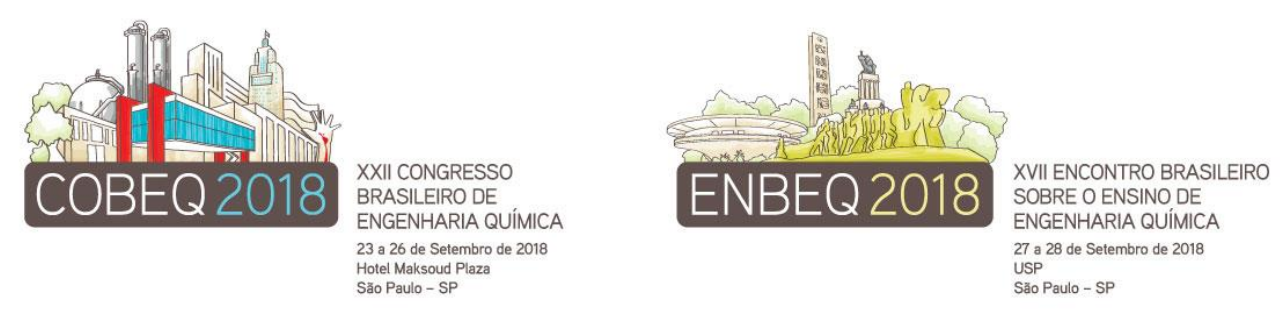

\title{
AVALIAÇÃO DA CORROSÃO DO ALUMÍNIO OBTIDO PELA FUNDIÇÃ̂O DE EMBALAGENS ALIMENTÍCIAS.
}

\author{
BAIA, A. C. $\mathrm{F}^{1}$, RAFAEL, T. $\mathrm{N}^{2}$ e CARDOSO FILHO J. C. $\mathrm{A}^{3}$ \\ ${ }^{1}$ Universidade Federal do Pará, Instituto de Tecnologia, Faculdade de Engenharia Química \\ ${ }^{2}$ Universidade Federal do Pará, Instituto de Tecnologia, Faculdade de Engenharia Química \\ ${ }^{3}$ Universidade Federal do Pará, Instituto de Tecnologia, Faculdade de Engenharia Química \\ E-mail para contato: anaclaudia.fonsecabaia@yahoo.com
}

\begin{abstract}
RESUMO -O presente trabalho teve por objetivo a realização de testes de corrosão em meio ácido (HCl 0,2 mol.L-1) e à temperatura ambiente do alumínio obtido pela fundição de embalagens alimentícias, considerando as diferentes posições de solidificação. Para os testes, foram utilizadas duas ligas de Alumínio com diferentes teores de Cobre, a primeira com 3\% de Cobre (Al-3\%Cu), e a segunda 5\% (Al-5\%Cu). O material foi lixado, furado e submetido aos testes. Os resultados mostraram que o desprendimento de gás Hidrogênio $\left(\mathrm{H}_{2}\right)$ foi nulo ou desprezível nos dez primeiros minutos de ensaio, a velocidade de corrosão diminuiu significativamente com o aumento do teor de $\mathrm{Cu}$ na liga. Para a liga Al-3\% Cu, as posições mais distantes do ponto inicial de extração de calor apresentaram maior resistência à corrosão, enquanto que para a liga $\mathrm{Al}-5 \% \mathrm{Cu}$, esse comportamento não foi observado.
\end{abstract}

\section{INTRODUÇÃO}

O alumínio é o terceiro metal mais abundante na crosta terrestre, possuindo excelentes propriedades físico-químicas (entre as quais se destacam o baixo peso específico, a alta condutividade térmica e elétrica), e tornou-se o metal não-ferroso mais consumido no mundo. É maleável, dúctil e apto para a mecanização e para a fundição (ABAL: Associação Brasileira do Alumínio, 2005). O alumínio e suas ligas são amplamente utilizados na indústria, dentre as quais vale ressaltar a indústria de alimentos, destacando a preparação de embalagens. Uma das principais vantagens de usar o alumínio em embalagens é a possibilidade de reciclar o material e manter grande parte das suas propriedades físico-químicas.

Assim, é interessante analisar quais propriedades são mantidas quando o alumínio é reciclado na forma pura ou em ligas, e considerar de qual maneira suas características são maximizadas. Um meio de se investigar tais questões é através da análise da velocidade de corrosão do alumínio em função do tempo e do meio em que se encontra. A resistência do alumínio a corrosão é proveniente da formação de uma fina camada de óxido na superfície do metal, conferindo-o proteção. Essa camada, presente no alumínio das embalagens alimentícias é conhecida como camada passivadora

\subsection{Justificativa}



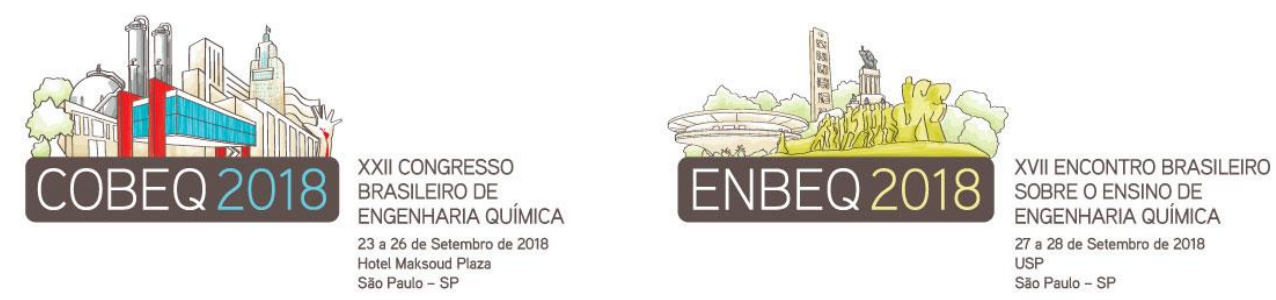

O alumínio puro tem uma excelente resistência à corrosão, mas possui uma resistência mecânica e dureza baixas, não servindo para determinadas aplicações. Por isso, outros elementos químicos, chamados de ligas, são adicionados para melhorar tais propriedades, aumentando dessa forma sua utilidade industrial

Dependendo da finalidade da liga produzida, outras propriedades podem ser modificadas de acordo com o elemento adicionado. De acordo com Callister (2002), as ligas apresentam características diferentes daquelas apresentadas pelos seus metais constituintes, tais como, dureza, ductilidade, condutividade, entre outras; além disso, as suas propriedades dependem da composição, microestrutura, tratamento térmico ou mecânico. As ligas mais comuns são o silício, cobre, magnésio, manganês e o zinco.

\subsection{Objetivos}

Realizar estudos do processo de corrosão em meio ácido $\left(\mathrm{HCl} 0,2\right.$ mol.L $\left.\mathrm{L}^{-1}\right)$ e à temperatura ambiente do alumínio obtido da fundição de embalagens alimentícias, determinando assim a cinética do material através da medida da evolução da pressão parcial do hidrogênio com o tempo, feita através de ensaios de perda de massa.

\section{MATERIAIS E MÉTODOS}

Para os ensaios de perda de massa, foram utilizadas ligas de $\mathrm{Al}-\mathrm{Cu}$ com diferentes teores de Cobre. A primeira continha 3\% de Cobre (Al-3\% Cu), e a segunda 5\% (Al-5\%Cu). De cada liga, foram escolhidos três corpos de prova, levando em consideração a posição dos mesmos durante a solidificação direcional horizontal das ligas-mãe, que foram divididas em sete partes. Na parte $n^{\circ} 1$ ocorreu a extração de calor mais rápida e na de $n^{\circ} 7$, a mais lenta. As peças escolhidas foram denominadas corpos de prova N2, N3 e N5 para Al-5\%Cu, e P'2, P'3 e P'4 para o $\mathrm{Al}-3 \% \mathrm{Cu}$. Os mesmos foram cortados, furados e lixados com lixas tipo mesh \#220, \#320, \#400 e \#600, respectivamente, adquirindo dimensões médias iguais a 1,57 x 1,42 x 0,24 cm.

Após a preparação, os corpos de prova foram imersos em um balão de fundo chato de $250 \mathrm{~mL}$ contendo uma solução de ácido clorídrico $0,2 \mathrm{~mol}$. $\mathrm{L}^{-1}$ e a temperatura ambiente de $25^{\circ} \mathrm{C}$. Simultaneamente o balão foi acoplado a um manômetro conforme mostrado na figura 1 , onde houve o monitoramento da liberação do gás $\mathrm{H}_{2}$.

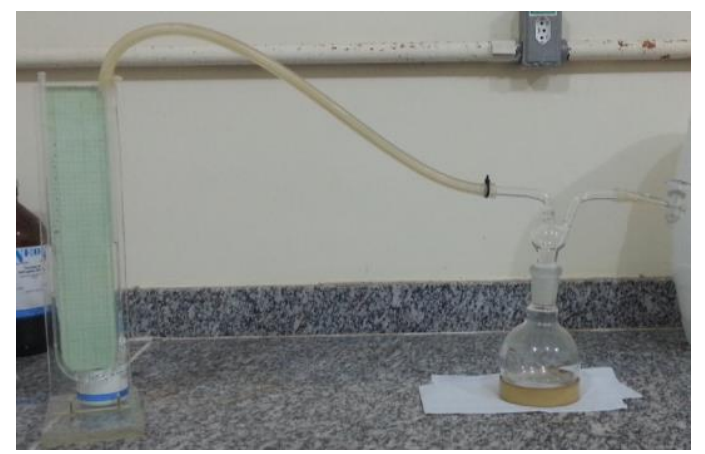

Figura 1: Sistema para captação de $\mathrm{H}_{2}$ 

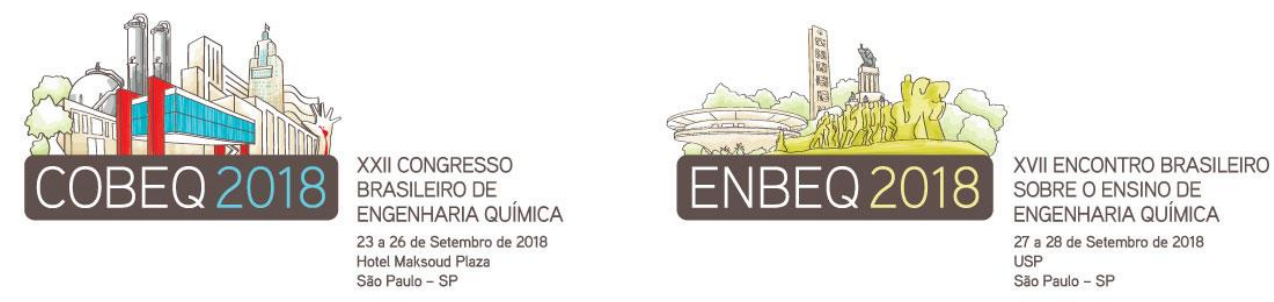

Podemos representar o processo de oxirredução que atinge os corpos de prova de $\mathrm{Al}$, através de duas semi-reações. São elas:

- $\mathrm{Al} \rightarrow \mathrm{Al}^{3+}+$ 3é (Reação anódica)

- $2 \mathrm{H}^{+}+2 \mathrm{e} \rightarrow \mathrm{H}_{2}$ (Reação catódica)

Nesse meio, vemos que o alumínio funciona como o agente redutor da reação, e sofre uma oxidação progressiva. Dessa forma, a solução ácida atua como o agente que provoca a oxidação, recebendo íons $\mathrm{Al}^{+3}$, e produzindo, através da redução, o gás $\mathrm{H}_{2}$, que é liberado. $\mathrm{O}$ volume de $\mathrm{H}_{2}$ liberado é proporcional à quantidade de alumínio desprendido.

\section{RESULTADOS}

Os ensaios de perda de massa de $\mathrm{Al}$ foram feitos em duplicata para todos os corpos de prova. Os gráficos de evolução de $\mathrm{H}_{2}$ correspondentes à cinética de corrosão das ligas de alumínio contendo 3\% e 5\% de Cu são apresentados nas Figuras 2 e 3, respectivamente.

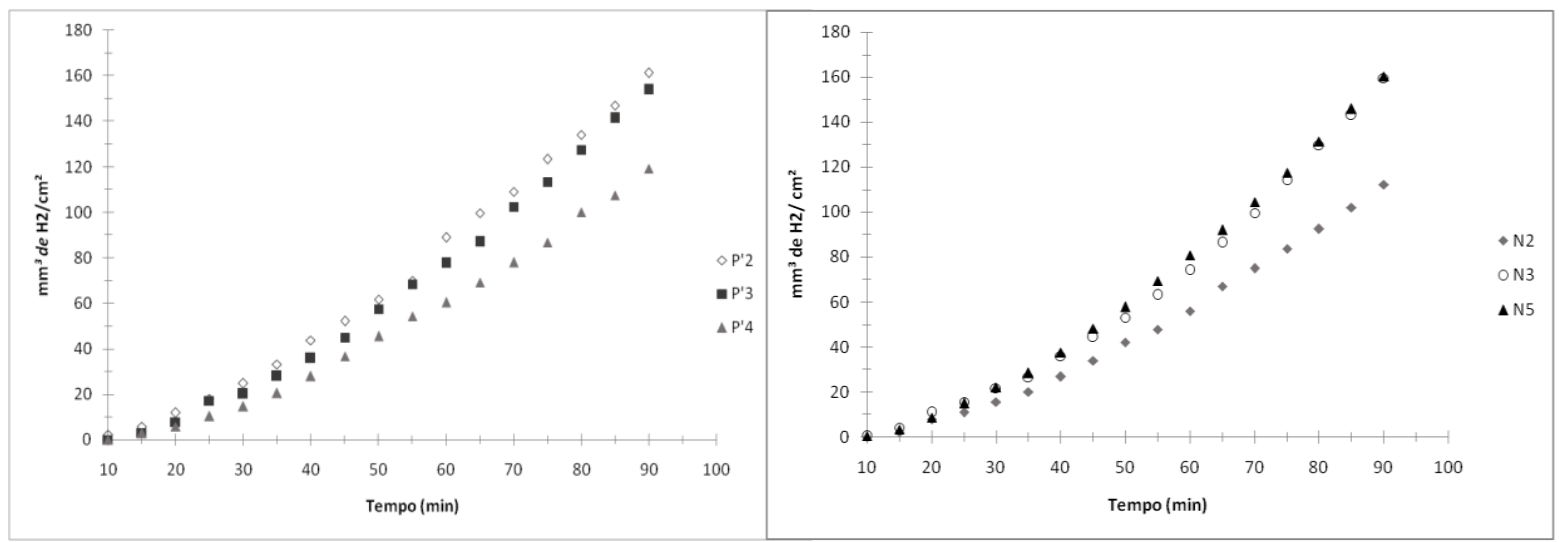

Figura 2: Ensaio de perda de massa para Al- Figura 3: Ensaio de perda de massa para Al$3 \% \mathrm{Cu}$ dos corpos de prova P'2, P'3 e P'4 em $5 \% \mathrm{Cu}$ dos corpos de prova N2, N3 e N4 em $\mathrm{HCl} \mathrm{0,2} \mathrm{M.}$

$\mathrm{HCl} \mathrm{0,2} \mathrm{M.}$

Os resultados de ambas as figuras mostram que o desprendimento de gás Hidrogênio $\left(\mathrm{H}_{2}\right)$ é nulo ou desprezível nos dez primeiros minutos de ensaio, independente do teor de Cobre na liga. Isso ocorre devido à camada passivadora $\left(\mathrm{Al}_{2} \mathrm{O}_{3}\right)$ que se forma na superfície do metal quando o mesmo entra em contato com o ar. Quando a camada passivadora é atacada e destruída pelo $\mathrm{HCl}$, passa a ocorrer de fato a corrosão do $\mathrm{Al}$ e desprendimento de $\mathrm{H}_{2}$.

Também podemos observar que a velocidade de corrosão diminui significativamente com o aumento do teor de $\mathrm{Cu}$ na liga, como ocorre com o corpo de prova P'2, que libera mais gás Hidrogênio do que o corpo de prova N2, que apresenta $5 \% \mathrm{Cu}$. (Figura 4). 


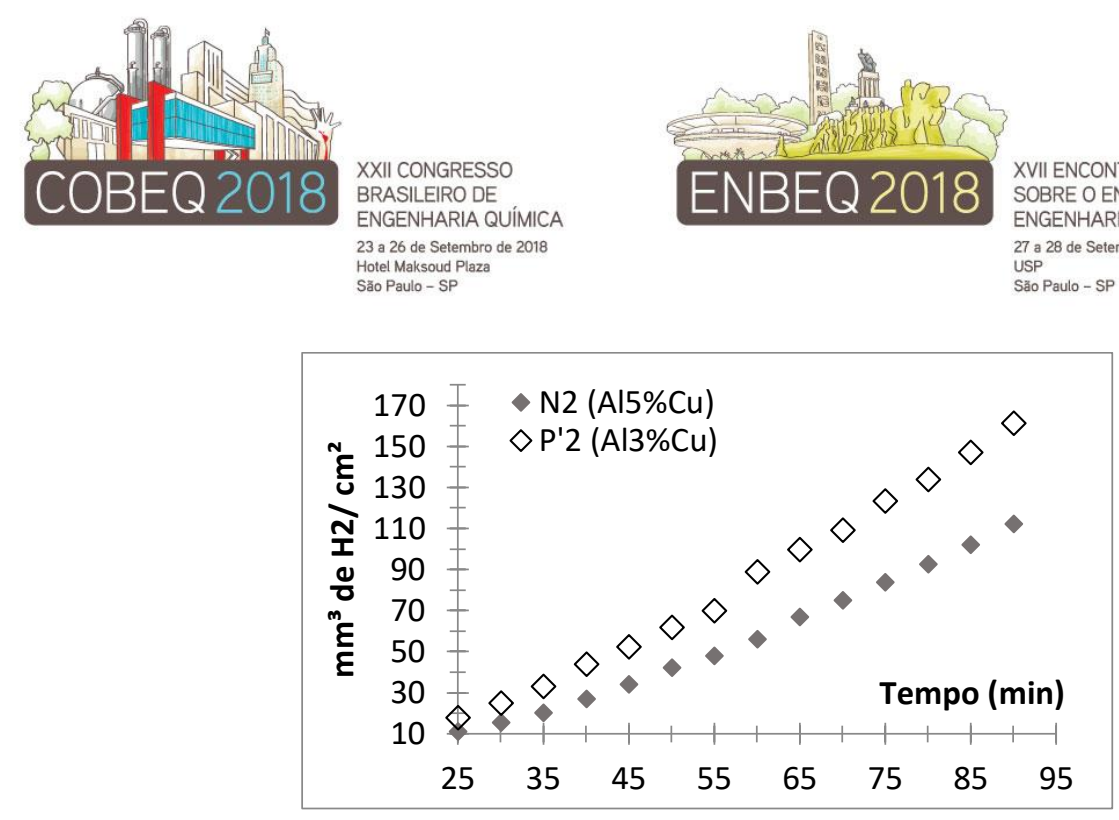

Figura 4: Gráfico comparativo entre as velocidades de corrosão levando em consideração o teor de $\mathrm{Cu}$ nas ligas.

\section{CONSIDERAÇÕES FINAIS}

Os resultados dos ensaios de corrosão mostraram que a quebra da camada passivadora acontece no mesmo intervalo (10 min.), independente da presença de $\mathrm{Cu}$ da liga metálica. A velocidade de corrosão é influenciada pelo teor de Cobre presente nas ligas estudadas, de forma que quanto mais significante a percentagem de $\mathrm{Cu}$, maior é a resistência da liga à corrosão em meio ácido.

Foi observado que o processo de solidificação influencia diretamente no desprendimento de gás $\mathrm{H} 2$, e relaciona-se também com o teor de $\mathrm{Cu}$. Para a liga $\mathrm{Al}-3 \% \mathrm{Cu}$, as posições mais distantes do ponto inicial de extração de calor apresentaram maior resistência à corrosão, enquanto que para a liga $\mathrm{Al}-5 \% \mathrm{Cu}$, esse comportamento não foi observado, visto que as posições onde o calor foi extraído de forma mais lenta nesta liga são as que têm maior velocidade de corrosão.

\section{REFERÊNCIAS BIBLIOGRÁFICAS}

FORGAÇA, J. $\quad$ R. V. Alumínio. Disponível em <http://www.alunosonline.com.br/quimica/aluminio.html> Data de acesso: 25 de agosto de 2015.

ALVES, F. O que é Alumínio e qual sua principal utilização? 2012. Disponível em $<$ http://www.industriahoje.com.br/o-que-e-aluminio-e-qual-sua-principal-utilizacao> Data de acesso: 27 de agosto de 2015 .

SANTOS, L. S., 2011, "Estudo eletroquímico de ligas metálicas alumínio - silício em meio ácido" Dissertação de mestrado, Universidade Federal do Pará.

MOREIRA, MARCELO F. Ligas de alumínio conformadas. Disponível em < www.dalmolim.com.br/educacao/materiais/biblimat/aluminioconf.pdf $>$ Data de acesso: 24 de agosto de 2015.

CHIAVERINE, V. Tratamento Térmico das Ligas Metálicas. S.I.: Associação Brasileira de Metalurgia e Materiais, 2003. 